This file was dowloaded from the institutional repository Brage NIH - brage.bibsys.no/nih

Reimers, C., Siafarikas, F., Stær-Jensen, J., Småstuen, M. C., Bø, K., Engh, M. E. 2018. Risk factors for anatomic pelvic organ prolapse at 6 weeks postpartum: a prospective observational study. International Urogynecology Journal, under utgivelse. doi:10.1007/s00192-018$3650-2$

Dette er siste tekst-versjon av artikkelen, og den kan inneholde små forskjeller fra forlagets pdf-versjon. Forlagets pdf-versjon finner du her:

http://dx.doi.org/10.1007/s00192-018-3650-2

This is the final text version of the article, and it may contain minor differences from the journal's pdf version. The original publication is available here: http://dx.doi.org/10.1007/s00192-018-3650-2 


\section{RISK FACTORS FOR ANATOMIC PELVIC ORGAN PROLAPSE AT SIX WEEKS POSTPARTUM: a prospective observational study}

Cathrine Reimers 1,2, Franziska Siafarikas 1, Jette Stær-Jensen 1, Milada Cvancarova Småstuen 3, Kari Bø 1,4, Marie Ellström Engh 1,5

1 Akershus University Hospital, Department of Obstetrics and Gynecology,

Lørenskog, Norway

2 Oslo University Hospital, Division of Gynecology and Obstetrics, Oslo, Norway

3 Oslo and Akershus University College of Applied Sciences, Faculty of Health Sciences,

Oslo, Norway

4 Norwegian School of Sport Sciences, Department of Sports Medicine, Oslo, Norway

5 University of Oslo, Faculty division Akershus University Hospital, Oslo, Norway

\section{Corresponding author}

Cathrine REIMERS, Consultant gynecologist.

Akershus University Hospital, Department of obstetrics and gynecology,

PO Box 1000, 1478 Lørenskog, Norway.

Telephone: +47950 87 720, Email: creimers@online.no

WORD COUNT ABSTRACT: 215

WORD COUNT MAIN TEXT: 2628

FINANCIAL DISCLAIMER/CONFLICT OF INTEREST: NONE

FUNDING: 
The study has been funded by the South-Eastern Norway Regional Health Authority and by the Research Council of Norway.

\section{ETHICAL APPROVAL:}

The Regional Ethics Committee (REK Southeast D 2009/170) and the Akershus University Hospital Privacy Ombudsman (2799026) approved the study. All participants gave their written informed consent before entering the study.

\section{CONTRIBUTION TO AUTHORSHIP:}

Results from this study were presented at the 2017 ICS conference, Florence, Italy, September 2017 (\# OP 24 ICS 2017).

CR: Idea for this paper, Data analyses, Manuscript writing

M Ellstöm Engh: Project development, Idea for this paper, Manuscript writing

K Bø: Project development, Manuscript editing

JE Stær-Jensen: Data collection, Manuscript editing

F Siafarikas: Data collection, Manuscript editing

MC Småstuen: Data analyses

All authors have revised the drafted article critically for important intellectual content, and have approved of the submitted article. 


\begin{abstract}
Objective: Identify risk factors for postpartum anatomic pelvic organ prolapse (aPOP) by comparing women with and without aPOP at six weeks postpartum with respect to pelvic floor measurements antepartum and obstetrical characteristics.
\end{abstract}

Design: Prospective observational cohort study including nulliparous pregnant women

Setting: Norwegian university hospital

Methods: Participants underwent clinical examinations including pelvic organ prolapse quantification system (POP-Q) and transperineal ultrasound at gestational week 21 and at six weeks postpartum. Background and obstetrical information was obtained from an electronic questionnaire and from the patient's electronic medical file, respectively. Associations were estimated using logistic regression analyses.

Main outcome measures: The dependent variable was aPOP defined as POP-Q stage $\geq 2$ at six weeks postpartum. Independent variables were mid pregnancy measurements of selected POP-Q variables and levator hiatus area (LHarea), delivery route, and the presence of major levator ani muscle (LAM) injuries at six weeks postpartum.

Results: A larger LHarea, a more distensible LAM, a longer distance from the meatus urethra to anus $(\mathrm{Gh}+\mathrm{Pb})$ and a more caudal position of the anterior vaginal wall $(\mathrm{Ba})$ at mid pregnancy were risk factors for aPOP at six weeks postpartum, while delivery route and presence of major LAM injuries were not.

Conclusion: Prelabour differences in the pelvic floor rather than obstetrical events were risk factors for aPOP at six weeks postpartum. 


\section{KEYWORDS:}

Pelvic organ prolapse, Pelvic floor, POP, Postpartum, Pregnancy.

\section{BRIEF SUMMARY}

Antepartum pelvic floor differences rather than obstetrical events were risk factors for POP at six weeks postpartum

\section{SHORT VERSION OF TITLE}

Risk factors for anatomic POP at six weeks postpartum 


\section{Introduction}

The etiology of pelvic organ prolapse (POP) is complex, and is shown to be multifactorial with heritage, increasing parity and age to be important risk factors (1-4). The integrated lifespan model presented by DeLancey et al(5) describes predisposing and inciting causal factors for the development of POP where childbirth is considered as an important inciting factor. The delay, often by several decades, from childbearing to the manifestation of POP is explained by an initial recovery of the pelvic floor postpartum. This initial recovery of the pelvic floor after pregnancy and delivery has made identification of risk factors related to childbearing challenging, and to date very few prospective studies exist. Retrospective and cross-sectional studies have suggested that major injuries to the levator ani muscle (LAM) are important risk factors for POP being present in one third of patients with POP, and exclusively in women who have delivered vaginally (6-8). An enlarged levator hiatus (LH) is another feature found to be associated both to POP and to childbearing, but whether caused by connective tissue weakness, pregnancy, childbirth injury or by the presence of the prolapse itself is debated (9-14).

The fact that most women who deliver vaginally will not develop POP, and that most women with POP do not have major LAM injuries, indicate that we are still far from understanding the complex etiology of POP and how childbearing interacts with the pelvic floor.

This study is part of a prospective observational study aiming at describing the natural history of the pelvic floor from mid pregnancy until one year postpartum in a cohort of first time mothers, using the pelvic organ prolapse quantification system (POP-Q) and transperineal three dimensional (3D) ultrasound (15-21). Data presented from this cohort has shown that pelvic organ support changed both during pregnancy and following delivery. Anatomic POP (aPOP) defined as POP-Q stage $\geq 2$ reached a peak prevalence of nine per cent at six weeks 
postpartum followed by a recovery to a prevalence of two per cent at one year postpartum (17). In the present study we wanted to study risk factors for having aPOP postpartum. To avoid the effect of the initial recovery of the pelvic floor that previously has made identification of risk factors related to childbearing challenging we chose to stratify our sample already at 6 weeks postpartum.

The aim of the present study was to identify possible predisposing and inciting risk factors for aPOP by comparing women with and without aPOP at six weeks postpartum with regards to predelivery characteristics such as pelvic floor measurements including POP-Q variables and LHarea at mid pregnancy, and obstetrical characteristics including delivery route and major LAM injuries identified at six weeks postpartum.

\section{Methods}

The present study is part of a prospective observational cohort study following 300 nulliparous pregnant women from mid pregnancy until one year postpartum. The study was conducted at Akershus University hospital in Norway from January 2010 to October 2012, and was approved by the Regional Ethics Committee (REK Sør-Øst D 2009/170) and the hospital Privacy Ombudsman (2799026). The participants gave their written informed consent to participate. The public healthcare system in Norway is organized in such a way that virtually all pregnant women within the geographic area of a hospital will attend the routine ultrasound examination in the second trimester at this hospital, and when due, will deliver at the same hospital. All healthcare related to pregnancy is free. Akershus University hospital is located in the vicinity of Oslo, and is one of the largest obstetric units in Norway with 4500 deliveries per year. During the inclusion period all nulliparous pregnant women aiming to 
deliver at the hospital received written information about the study together with the invitation for routine ultrasound examination at 18-22 weeks of gestation. Following the ultrasound examination women with a singleton pregnancy and Scandinavian language skills were invited to participate in the study by the project coordinator. Exclusion criteria were serious illness to mother or fetus, prior pregnancy of more than 16 weeks gestation, and missing POPQ data at six weeks postpartum. Continuing exclusion criteria were premature delivery prior to 32 weeks of gestation and stillbirth. The women included in the cohort have been shown to be comparable to the total population of nulliparous pregnant women who delivered at the hospital during the inclusion period $(\mathrm{n}=2621)$ with regards to age, body mass index (BMI), fetal birth weight and delivery route, but more women in the study sample had university or college education $(75.3 \%$ compared with $50.8 \%, \mathrm{P}<0.001)(17)$. The study participants were predominantly of Caucasian ethnicity $(96 \%)$.

An electronic questionnaire answered by the participants provided background information, while obstetric data was obtained from the woman's electronic medical file in the hospital (DIPS / PARTUS C). The clinical examinations were performed at mid pregnancy and at 6 weeks postpartum by two trained gynecologists blinded to previous findings and the obstetric history of the participants. POP-Q was done according to standardized methods previously described in detail (17). Transperineal 3D ultrasound describing LHarea and major LAM injuries was done according to the methods described by Dietz defining major LAM injuries by a defect in the muscle evident in at least three consecutive tomographic slices at and/or above the plane of minimal hiatal dimension (22). Reliability for assessments of LH area and major LAM injuries has been tested and found to be good in separate studies from this cohort $(20,21)$.

The dependent variable was aPOP defined as POP-Q stage $\geq 2$ at six weeks postpartum. 
Independent variables were:

A) Pelvic floor measurements at mid pregnancy including selected POP-Q variables representing the three vaginal compartments $(\mathrm{Ba}, \mathrm{Bp}, \mathrm{C})$ and the sum of the two measurements of the external genitalia $(\mathrm{Gh}$ and $\mathrm{Pb})$ as well as LHarea at rest and Valsalva. LAM distensibility was estimated by calculating the difference in LHarea from rest to Valsalva $\left(\mathrm{cm}^{2}\right)$.

B) Delivery route, and the presence of major LAM injuries at six weeks postpartum.

There was no a priori power calculation done for this study.

\section{$\underline{\text { Statistical methods }}$}

Background variables, pelvic floor measurements and obstetrical variables are presented as mean (SD), or as counts (percentages) as appropriate. Differences between the two groups were tested by the use of chi square test for categorical variables, and with independent samples T-test for continuous variables.

Possible crude association between aPOP at six weeks postpartum and the following variables; LHarea at Valsalva, LAM distensibility, $\mathrm{Ba}$, and $\mathrm{Gh}+\mathrm{Pb}$ at gestational week 21, delivery route, and presence of Major LAM injuries at six weeks postpartum, were analyzed using univariate logistic regression models. In addition each of the above described models was adjusted for maternal age and body mass index at gestational week 21 .

All tests were two-sided and p-values $<0.05$ were considered statistically significant.

All statistical analyses were performed using SPSS v 20.0. 


\section{Results}

Of the 300 women included in the cohort at gestational week 21, five women had been excluded, ten had dropped out and one refused POP-Q examination at six weeks postpartum, leaving 284 women with POP-Q data to constitute our study sample. Background and obstetrical characteristics did not differ between women remaining in the study and women lost to follow up (data not shown).

At six weeks postpartum 25 women (9\%) had aPOP defined as POP-Q stage $\geq 2$, of which twenty-two had POP-Q stage 2 anterior prolapse and three had POP-Q stage 2 posterior prolapse. Table 1 shows maternal characteristics at gestational week 21 , and obstetrical characteristics recorded either at delivery or at six weeks postpartum for the total study sample and for the women with and without aPOP at six weeks postpartum. There were no statistically significant differences between women with and without aPOP regarding maternal age, height, weight or body mass index (BMI) at 21 weeks of gestation.

Women with aPOP at six weeks postpartum had a more caudal position of the anterior vaginal wall $(\mathrm{Ba})$, and a longer distance from the meatus urethra to the anus $(\mathrm{Gh}+\mathrm{Pb})$. There were no differences in the position of the cervix (c) or the posterior vaginal wall (Bp) between the two groups.

Women with aPOP had a larger LHarea at rest and at Valsalva, as well as a more distensible LAM at gestational week 21 compared to women without aPOP at six weeks postpartum.

Comparing obstetrical data between the two groups, our data did not reveal any differences in gestational age at birth, fetal birth weight, or maternal height / fetal birth weight ratio. Differences in vaginal versus abdominal delivery rate was not statistically significant. The subgroups of delivery mode (normal vaginal delivery versus operative vaginal delivery and 
prelabour versus intralabour caesarean delivery) were too small for meaningful statistical analyses. It is worth noting that one woman with postpartum aPOP had caesarean delivery at $3 \mathrm{~cm}$ cervical dilatation due to failure to progress. There was no difference in episiotomy-rate between the vaginal deliveries in the two groups. The ten women in this cohort diagnosed with anal sphincter injury were all in the non-aPOP group.

The difference in prevalence of major LAM injuries was not statistically significant between women with $(6 / 25=24 \%)$ and without $(40 / 259=15 \%)$ aPOP at six weeks postpartum.

Table 2 presents crude and adjusted odds ratios (OR) for the association between aPOP at six weeks postpartum and the following variables; LHarea at Valsalva, LAM distensibility, Ba, and $\mathrm{Gh}+\mathrm{Pb}$ measured at mid pregnancy, delivery route, and presence of major LAM injuries at six weeks postpartum. Women with larger LHarea at Valsalva, a more distensible LAM, a more caudal position of $\mathrm{Ba}$ and a longer distance from the meatus urethra to anus $(\mathrm{Gh}+\mathrm{Pb})$ at mid pregnancy had a higher risk of aPOP at six weeks postpartum. Adjusting for maternal age and BMI did not alter these associations. Delivery route and Major LAM injuries were not associated to aPOP at six weeks postpartum.

\section{Discussion}

\section{$\underline{\text { Main findings }}$}

Comparing women with and without aPOP at six weeks postpartum with regard to predisposing factors and obstetrical inciting factors we found that most pelvic floor measurements were different already in pregnancy while there were no statistically significant differences in delivery route or presence of major LAM injuries.

\section{$\underline{\text { Strength and limitations }}$}


Major strengths of this study are the comparatively large sample size and the prospective longitudinal design. Given that pelvic organ support changes over time both ante- and postpartum, the fixed time points relative to delivery for the assessments is another strength of this study.

Limitations of this study are the lack of data prior to, and from early pregnancy. A follow up of 10-20 years after delivery would have enabled us to test the assumption that women with transient aPOP after childbearing have a higher risk of manifest aPOP later in life. Another limitation is that the POP-Q system is not validated for women in pregnancy or postpartum.

Despite having a comparatively large cohort followed longitudinally with clinical assessments of the pelvic floor, anatomic POP had a low prevalence, increasing the risk of type II error when evaluating whether LAM injuries and delivery route are risk factors for aPOP at six weeks postpartum.

\section{$\underline{\text { Interpretation }}$}

Finding that prelabour differences in the pelvic floor, rather than obstetrical events, were risk factors for aPOP at six weeks postpartum, are in agreement with a prospective study by Sze et al finding that the proportion of women who had a stage II pelvic organ prolapse 6 weeks after spontaneous vaginal delivery was significantly higher in those with antepartum prolapse than those without antepartum pelvic support defect (23). Our findings are also in agreement with a study by van Veelen et al that found an increase during pregnancy in LH area and LH distensibility that persisted after childbirth independent of delivery mode, and hypothesize that this increased pelvic floor distensibility may play a role in the development of pelvic floor dysfunction later in life(24). A recent study from 2017 finding that enlarged LH area postpartum was not associated to intrapartum characteristics is also coherent with our 
results(13). The finding that antepartum differences rather than obstetrical exposures were associated to postpartum aPOP supports genetic predisposition to be an important etiologic factor for POP. This is coherent with a study by Durnea et al(25) stating that the association between uterine prolapse and collagen III level, and the lack of correlation between mode of delivery and uterine prolapse grade is suggestive of an important congenital contribution to POP etiology. It is also coherent with a systematic review by Lince et al finding that women with POP are substantially more likely to have family members with the same condition compared to women without POP(4), and with a study by Dietz et al showing that bladder neck mobility is a heritable trait(26).

Comparing women with and without postpartum aPOP we find that both static and dynamic pelvic floor properties differ between the two groups at mid pregnancy. Whether these differences were apparent already prior to pregnancy or whether the women with postpartum aPOP simply respond differently to the hormones and increased mechanical stress of pregnancy this study is not designed to find out. A longitudinal study including women very early or prior to pregnancy could help explore these questions further.

The role of an enlarged LH area as a risk factor for POP seems to be complex; An enlarged LH has been attributed either to muscle or nerve injury caused by vaginal childbirth (10) or to the presence of the prolapse itself (11), but according to our results, an enlarged LH in women with postpartum aPOP is a trait not only preceding the development of $\mathrm{POP}$, it is also preceding childbirth. A traumatically enlarged LH following major LAM injury is well documented (27), but seems to represent a different matter altogether, mainly affecting women with an initially small and non-compliant LH (19). This heterogeneity of causes for enlarged LH area might explain why a cross sectional study of urogynaecological patients found that major LAM injuries and enlarged LH were independent risk factors for POP (12). 
We suggest that future research should differentiate between enlarged LH area with and without concurrent major LAM injury.

A constitutionally enlarged LH area seems to have a dual role; it is shown to enable uncomplicated vaginal delivery $(14,18,28)$, but it may also increase the risk of aPOP later in life. This study shows that an enlarged LH area antepartum increases the risk of transient aPOP at six weeks postpartum, but whether it also increases the risk of manifest aPOP later in life needs to be explored in studies with longer follow-up.

The lack of association between aPOP and LAM injury shortly after delivery is in agreement with a study by Laterza et al (29), and is not contradictory to LAM injuries being an important risk factor for POP, it simply suggests that LAM injuries do usually not cause anatomic prolapse in the short term after childbirth. A recent study by Thomas et al shows that mean latency between first birth and presentation for prolapse surgery in women with avulsion was 33.5 (range 3-66) years (30). The fact that major LAM injuries is only found in one third of women with aPOP(6-8) shows that causal factors other than major LAM injuries are important in the etiology of POP.

The lack of association between delivery route and postpartum aPOP might be due to lack of statistical power, but the finding that one participant had aPOP after caesarean delivery on 3 $\mathrm{cm}$ cervical dilatation demonstrates that (unlike major LAM injuries) vaginal delivery is not a prerequisite for postpartum aPOP.

\section{Conclusion}


Prelabour differences in the pelvic floor rather than obstetrical events were risk factors for aPOP at six weeks postpartum.

To further increase our understanding of the natural history of POP, larger studies comparing dynamic properties of the pelvic floor during pregnancy to prolapse status both in the short and the long term postpartum are needed. 


\section{ACKNOWLEDGEMENTS:}

The authors would like to thank the women who participated in the study and midwife Tone Breines Simonsen who administered the assembling and follow-up of the cohort. We would also like to thank the physiotherapists Gunvor Hilde and Kristin Gjestland for data analysis of the ultrasound volumes. 


\section{REFERENCES:}

1. Mant J, Painter R, Vessey M. Epidemiology of genital prolapse: observations from the Oxford Family Planning Association Study. Br J Obstet Gynaecol. 1997;104(5):579-85.

2. Swift S, Woodman P, O'Boyle A, Kahn M, Valley M, Bland D, et al. Pelvic Organ Support Study (POSST): the distribution, clinical definition, and epidemiologic condition of pelvic organ support defects. Am J Obstet Gynecol. 2005;192(3):795-806.

3. Miedel A, Tegerstedt G, Maehle-Schmidt M, Nyren O, Hammarstrom M. Nonobstetric risk factors for symptomatic pelvic organ prolapse. Obstet Gynecol. 2009;113(5):1089-97.

4. Lince SL, van Kempen LC, Vierhout ME, Kluivers KB. A systematic review of clinical studies on hereditary factors in pelvic organ prolapse. International urogynecology journal. 2012;23(10):132736.

5. DeLancey JOL, Kane Low L, Miller JM, Patel DA, Tumbarello JA. Graphic integration of causal factors of pelvic floor disorders: an integrated life span model. Am J Obstet Gynecol. 2008;199(6):610.e1-.e5.

6. Albrich S, Rommens K, Steetskamp J, Weyer V, Hoffmann G, Skala C, et al. Prevalence of Levator Ani Defects in Urogynecological Patients. Geburtshilfe Frauenheilkd. 2015;75(1):51-5.

7. Volloyhaug I, Morkved S, Salvesen KA. Association between pelvic floor muscle trauma and pelvic organ prolapse 20 years after delivery. International urogynecology journal. 2016;27(1):39-45. 8. Dietz HP, Simpson JM. Levator trauma is associated with pelvic organ prolapse. BJOG. 2008;115(8):979-84.

9. Shek KL, Kruger J, Dietz HP. The effect of pregnancy on hiatal dimensions and urethral mobility: an observational study. International urogynecology journal. 2012;23(11):1561-7.

10. Shek KL, Dietz HP. The effect of childbirth on hiatal dimensions. Obstet Gynecol. 2009;113(6):1272-8.

11. Andrew BP, Shek KL, Chantarasorn V, Dietz HP. Enlargement of the levator hiatus in female pelvic organ prolapse: cause or effect? Aust N Z J Obstet Gynaecol. 2013;53(1):74-8.

12. Dietz HP, Franco AV, Shek KL, Kirby A. Avulsion injury and levator hiatal ballooning: two independent risk factors for prolapse? An observational study. Acta Obstet Gynecol Scand. 2012;91(2):211-4.

13. Caudwell-Hall J, Kamisan Atan I, Martin A, Guzman Rojas R, Langer S, Shek K, et al. Intrapartum predictors of maternal levator ani injury. Acta Obstet Gynecol Scand. 2017;96(4):426-31. 14. Toozs-Hobson P, Balmforth J, Cardozo L, Khullar V, Athanasiou S. The effect of mode of delivery on pelvic floor functional anatomy. Int Urogynecol J Pelvic Floor Dysfunct. 2008;19(3):40716.

15. Staer-Jensen J, Siafarikas F, Hilde G, Bo K, Engh ME. Ultrasonographic evaluation of pelvic organ support during pregnancy. Obstet Gynecol. 2013;122(2 Pt 1):329-36.

16. Staer-Jensen J, Siafarikas F, Hilde G, Benth JS, Bo K, Engh ME. Postpartum recovery of levator hiatus and bladder neck mobility in relation to pregnancy. Obstet Gynecol. 2015;125(3):531-9.

17. Reimers C, Staer-Jensen J, Siafarikas F, Saltyte-Benth J, Bo K, Ellstrom Engh M. Change in pelvic organ support during pregnancy and the first year postpartum: a longitudinal study. BJOG. 2016;123(5):821-9.

18. Siafarikas F, Staer-Jensen J, Hilde G, Bo K, Ellstrom Engh M. Levator hiatus dimensions in late pregnancy and the process of labor: a 3- and 4-dimensional transperineal ultrasound study. Am J Obstet Gynecol. 2014;210(5):484.e1-7.

19. Siafarikas F, Staer-Jensen J, Hilde G, Bo K, Ellstrom Engh M. The levator ani muscle during pregnancy and major levator ani muscle defects diagnosed postpartum: a three- and fourdimensional transperineal ultrasound study. BJOG. 2015;122(8):1083-91.

20. Staer-Jensen J, Siafarikas F, Hilde G, Braekken IH, Bo K, Engh ME. Pelvic floor muscle injuries 6 weeks post partum-an intra- and inter-rater study. Neurourol Urodyn. 2013;32(7):993-7. 
21. Siafarikas F, Staer-Jensen J, Braekken IH, Bo K, Engh ME. Learning process for performing and analyzing 3D/4D transperineal ultrasound imaging and interobserver reliability study. Ultrasound Obstet Gynecol. 2013;41(3):312-7.

22. Dietz HP, Bernardo MJ, Kirby A, Shek KL. Minimal criteria for the diagnosis of avulsion of the puborectalis muscle by tomographic ultrasound. International urogynecology journal. 2011;22(6):699-704.

23. Sze EH, Sherard GB, 3rd, Dolezal JM. Pregnancy, labor, delivery, and pelvic organ prolapse. Obstet Gynecol. 2002;100(5 Pt 1):981-6.

24. van Veelen GA, Schweitzer KJ, van der Vaart $\mathrm{CH}$. Ultrasound imaging of the pelvic floor: changes in anatomy during and after first pregnancy. Ultrasound Obstet Gynecol. 2014;44(4):476-80. 25. Durnea CM, Khashan AS, Kenny LC, Durnea UA, Smyth MM, O'Reilly BA. Prevalence, etiology and risk factors of pelvic organ prolapse in premenopausal primiparous women. International urogynecology journal. 2014;25(11):1463-70.

26. Dietz HP, Hansell NK, Grace ME, Eldridge AM, Clarke B, Martin NG. Bladder neck mobility is a heritable trait. BJOG. 2005;112(3):334-9.

27. Abdool Z, Shek KL, Dietz HP. The effect of levator avulsion on hiatal dimension and function. Am J Obstet Gynecol. 2009;201(1):89.e1-5.

28. Oliphant SS, Nygaard IE, Zong W, Canavan TP, Moalli PA. Maternal adaptations in preparation for parturition predict uncomplicated spontaneous delivery outcome. Am J Obstet Gynecol. 2014;211(6):630 e1-7.

29. Laterza RM, Schrutka L, Umek W, Albrich S, Koelbl H. Pelvic floor dysfunction after levator trauma 1-year postpartum: a prospective case-control study. International urogynecology journal. 2015;26(1):41-7.

30. Thomas V, Shek KL, Guzman Rojas R, Dietz HP. Temporal latency between pelvic floor trauma and presentation for prolapse surgery: a retrospective observational study. International urogynecology journal. 2015;26(8):1185-9. 
Table 1: Descriptive statistics of the study sample;

Maternal characteristics and pelvic floor measurements at gestational week 21 and obstetrical characteristics.

\begin{tabular}{|c|c|c|c|}
\hline & $\begin{array}{l}\text { Total study sample } \\
\mathrm{N}=284\end{array}$ & $\begin{array}{l}\text { Women without } \\
\text { aPOP } 6 \text { weeks postpartum } \\
\mathrm{N}=259\end{array}$ & $\begin{array}{l}\text { Women with } \\
\text { aPOP } 6 \text { weeks postpartum } \\
\mathrm{N}=25\end{array}$ \\
\hline Maternal characteristics at gw 21 & Mean (SD) & Mean (SD) & Mean (SD) \\
\hline Maternal age (years) & $28.7(4.3)$ & $28.6(4.3)$ & $30.1(4.4)$ \\
\hline Maternal height (m) & $1.68(0.6)$ & $1.68(0.1)$ & $1.67(0.1)$ \\
\hline Maternal BMI $\left(\mathrm{kg} / \mathrm{m}^{2}\right)$ & $25.8(3.9)$ & $25.7(3.9)$ & $26.7(3.7)$ \\
\hline \multicolumn{4}{|l|}{ Pelvic floor measurements at gw 21} \\
\hline Levator hiatus area at Valsalva $\left(\mathrm{cm}^{2}\right)$ & \multirow{3}{*}{$\begin{array}{l}15.4(4.9) \\
11.7(2.2) \\
3.7(3.7)\end{array}$} & $15.1(4.7)^{*}$ & $18.8(5.3)^{*}$ \\
\hline Levator hiatus area at rest $\left(\mathrm{cm}^{2}\right)$ & & $11.6(2.2)^{*}$ & $12.9(2.0)^{*}$ \\
\hline LAM distensibility $\left(\mathrm{cm}^{2}\right)$ & & $3.5(3.7)^{*}$ & $5.9(4.1)^{*}$ \\
\hline $\mathrm{Ba}$ & $-2.7(0.5)$ & $-2.7(0.5)^{*}$ & $-2.4(0.7)^{*}$ \\
\hline Bp & $-2.9(0.4)$ & $-2.9(0.4)$ & $-2.8(0.4)$ \\
\hline $\mathrm{C}$ & $-7.6(1.0)$ & $-7.6(1.0)$ & $-7.7(1.2)$ \\
\hline $\mathrm{Gh}+\mathrm{Pb}(\mathrm{cm})$ & $7.2(1.1)$ & $7.2(1.1)^{*}$ & $7.8(1.1)^{*}$ \\
\hline \multicolumn{4}{|l|}{ Obstetrical characteristics } \\
\hline Gestational age at birth (Weeks) & $40.1(1.5)$ & $40.1(1.5)$ & $40.2(1.4)$ \\
\hline Foetal birth weight (gram) & $3497(508)$ & $3493(514)$ & $3538(443)$ \\
\hline \multirow{2}{*}{$\begin{array}{l}\text { Maternal height / foetal birth weight- } \\
\text { ratio }(\mathrm{m} / \mathrm{kg})\end{array}$} & $0.4898(0.08)$ & $0.4909(0.08)$ & $0.4787(0.06)$ \\
\hline & $\mathrm{N}(\%)$ & $\mathrm{N}(\%)$ & $\mathrm{N}(\%)$ \\
\hline Vaginal delivery & $241(85 \%)$ & $217(84 \%)$ & $24(96 \%)$ \\
\hline - $\quad$ Normal vaginal delivery & - $196(69 \%)$ & - $177(68 \%)$ & - $19(76 \%)$ \\
\hline - Vacuum delivery & - $41(14 \%)$ & - $36(14 \%)$ & - $5(20 \%)$ \\
\hline $\begin{array}{l}\text { Forceps or combined vacuum } \\
\text { and forceps delivery }\end{array}$ & - $\quad 4(1 \%)$ & - $4(1 \%)$ & $\bullet$ \\
\hline Caesarean delivery & $43(15 \%)$ & $42(16 \%)$ & $1(4 \%)$ \\
\hline $\begin{array}{ll}\text { - } & \text { Prelabour (cervical } \\
& \text { dilatation }<3 \mathrm{~cm}) \\
\text { - } & \text { Intralabour }(\mathrm{cervical} \\
\text { dilatation } \geq 3 \mathrm{~cm})\end{array}$ & $\begin{array}{ll}\text { - } & 21(7 \%) \\
\text { - } & 22(8 \%)\end{array}$ & $\begin{array}{ll}\text { - } & 21(8 \%) \\
\text { - } & 21(8 \%)\end{array}$ & $\begin{array}{ll}- & - \\
\text { - } & 1(4 \%)\end{array}$ \\
\hline Mediolateral episiotomy & $76(27 \%)$ & $66(25 \%)$ & $8(32 \%)$ \\
\hline Obstetric anal sphincter injury & $10(4 \%)$ & $10(4 \%)$ & - \\
\hline Major LAM injuries 6 weeks postpartum & $46(16 \%)$ & $40(15 \%)$ & $6(24 \%)$ \\
\hline
\end{tabular}

$\mathrm{aPOP}=$ anatomic pelvic organ prolapse, $\mathrm{gw}=$ gestational week, $\mathrm{SD}=$ standard deviation, $\mathrm{BMI}=$ Body mass index, $\mathrm{LAM}=$ levator ani muscle.

* Statistically significant difference with $\mathrm{p}<0.05$ 
Table 2:

Logistic regression analysis of association between possible risk factors and anatomic pelvic organ prolapse (aPOP) at six weeks postpartum

\begin{tabular}{|c|c|c|c|c|c|c|}
\hline & \multicolumn{6}{|c|}{ aPOP 6 weeks postpartum } \\
\hline Variable & $\begin{array}{c}\text { Crude } \\
\text { OR }\end{array}$ & {$[95 \% \mathrm{CI}]$} & p-value & $\begin{array}{l}\text { Adjusted } \\
\text { OR }\end{array}$ & {$[95 \% \mathrm{CI}]$} & p-value \\
\hline Ba at gw $21(\mathrm{~cm})$ & 2.49 & $\begin{array}{l}1.33- \\
4.64]\end{array}$ & $<0.01$ & 2.45 & $\begin{array}{l}{[1.29-} \\
4.67]\end{array}$ & $<0.01$ \\
\hline $\mathrm{Gh}+\mathrm{Pb}$ at $\mathrm{gw} 21(\mathrm{~cm})$ & 1.65 & $\begin{array}{l}{[1.12-} \\
2.44]\end{array}$ & 0.01 & 1.58 & $\begin{array}{l}{[1.05-} \\
2.38]\end{array}$ & 0.03 \\
\hline $\begin{array}{l}\text { LHareaValsalva at } \mathrm{gw} \\
21\left(\mathrm{~cm}^{2}\right)\end{array}$ & 1.13 & $\begin{array}{c}1.05- \\
1.21]\end{array}$ & $<0.01$ & 1.11 & $\begin{array}{l}{[1.04-} \\
1.20]\end{array}$ & $<0.01$ \\
\hline $\begin{array}{l}\text { LAM distensibility at } \\
\text { gw } 21 \text {, rest to } \\
\text { Valsalva }\left(\mathrm{cm}^{2}\right)\end{array}$ & 1.14 & $\begin{array}{c}1.04- \\
1.25]\end{array}$ & $<0.01$ & 1.13 & $\begin{array}{c}{[1.03-} \\
1.23]\end{array}$ & 0.01 \\
\hline $\begin{array}{l}\text { Major LAM injury at } \\
\text { 6wpp } \\
\text { - Yes } \\
\text { - No injury } \\
\text { (ref) }\end{array}$ & $\begin{array}{c}1.73 \\
1\end{array}$ & $\begin{array}{c}{[0.65-} \\
4.60]\end{array}$ & 0.27 & 1.90 & $\begin{array}{c}{[0.70-} \\
5.15]\end{array}$ & 0.21 \\
\hline $\begin{array}{l}\text { Delivery route } \\
\begin{array}{l}\text { - } \\
\text { delivery } \\
\text { - } \\
\text { Caesarean } \\
\text { delivery (ref) }\end{array}\end{array}$ & $\begin{array}{c}4.65 \\
1\end{array}$ & $\begin{array}{l}{[0.61-} \\
35.28]\end{array}$ & 0.14 & 5.69 & $\begin{array}{l}{[0.73-} \\
44.14]\end{array}$ & 0.10 \\
\hline
\end{tabular}

$\mathrm{CI}=$ confidence interval, $\mathrm{OR}=$ Odds Ratio, $\mathrm{LHarea}=\mathrm{Levator}$ ani hiatus area, $\mathrm{LAM}=$ Levator ani muscle, $\mathrm{gw}=$ gestational week, $\mathrm{wpp}=$ weeks postpartum.

In the adjusted OR each variable is adjusted for maternal age and body mass index. 